\title{
Clinical outcomes of dental implants combined with limited orthodontic treatment: A retrospective case series study
}

\author{
Il-hyung Kim ${ }^{1,2}$, Hyeong Gi Kim ${ }^{1,2}$, Pil-Young Yun ${ }^{1}$, Young-Kyun Kim ${ }^{1,3}$ \\ ${ }^{1}$ Department of Oral and Maxillofacial Surgery, Section of Dentistry, Seoul National University Bundang Hospital, Seongnam, \\ ${ }^{2}$ Office of Human Resources Development, Armed Forces Capital Hospital, Armed Forces Medical Command, Seongnam, \\ ${ }^{3}$ School of Dentistry \& Dental Research Institute, Seoul National University, Seoul, Korea
}

Purpose: Patients who visit a dental clinic for molar implant therapy often present with extruded opposing teeth or inclined adjacent teeth. In such cases, if implant therapy is performed with limited orthodontic treatment, the natural tooth structure can be preserved as much as possible. These treatment methods are conducted frequently, but most related studies have been confined to case reports. This study is considered meaningful because it is the first report to review and analyze the prognosis of dental implants with limited orthodontics.

Materials and Methods: From 2010 to 2017, among the patients who underwent implant therapy at Seoul National University Bundang Hospital, those who also underwent limited orthodontic treatment were investigated. Eleven implants placed in 11 patients were analyzed retrospectively. 3D modeling software with scanned diagnostic models was used to evaluate the improvement in the horizontal or vertical occlusal relationship through limited orthodontics. The prognosis for the tooth undergoing orthodontic treatment was also evaluated.

Results: The average age of the 11 patients (four males and seven females) was 46.7 years, ranging from 26 to 63 years. All 11 implants placed in the posterior region survived without complications for an average of 36.7 months after functioning. Nine out of 10 implants met the success criteria. An average of 11.4 months was required to upright the inclined posterior teeth, and an average of $3.2 \mathrm{~mm}$ of space was gained. The extruded molars were intruded by an average of $2.1 \mathrm{~mm}$ over an average of 13.5 months. One of the teeth that had undergone molar uprighting was extracted because of the increased mobility after 27.0 months of orthodontic treatment completion, and none of the remaining 10 teeth exhibited significant findings.

Conclusions: Dental implant therapy accompanied by limited orthodontic treatment could be considered a good treatment method that produces a satisfactory prognosis. (JOURNAL OF DENTAL IMPLANT RESEARCH 2021;40(1):1-9)

Key Words: Dental implants, Orthodontics, Dental occlusion

\section{INTRODUCTION}

As implant dentistry has developed, implant therapy is becoming one of the most common treatment methods performed in dental clinics. Implant dentistry is shifting the paradigm of prosthodontic treatment in that it can restore edentulism while preserving adjacent natural teeth. In particular, implant therapy is considered the treatment of choice for rehabilitation of small segments of edentu- lism such as single or double tooth loss.

Clinicians often come across cases involving extrusion of opposing teeth or tilted adjacent teeth around the missing teeth among patients who visit the clinic for implant treatment. These situations contribute to treatment plan complications. If interocclusal space is insufficient, a prosthesis of an appropriate occlusal thickness cannot be fabricated, and issues may occur due to the incongruity of the occlusal plane. In addition, posterior teeth that are

Received November 16, 2020, Revised December 28, 2020, Accepted January 2, 2021.

(c) Journal of Dental Implant Research.

(i) This is an open access article distributed under the terms of the Creative Commons Attribution Non-Commercial License (http://creativecommons.org/licenses/by-nc/4.0) which permits unrestricted non-commercial use, distribution, and reproduction in any medium, provided the original work is properly cited.

Correspondence to: Young-Kyun Kim, Department of Oral and Maxillofacial Surgery, Section of Dentistry, Seoul National University Bundang Hospital, 82 Gumi-ro, 173 beon-gil, Bundang-gu, Seongnam 13620, Korea. Tel: +82-31-787-7541, Fax: +82-31-787-4068, E-mail: kyk0505@daum.net 
tilted toward the missing tooth narrow the mesiodistal space, complicating implant treatment ${ }^{1,2)}$. In such cases, to properly restore the missing teeth while preserving the structural integrity of the natural teeth, it is necessary to create spatial adjustments through limited orthodontics prior to implant treatment.

Dental implant therapy with limited orthodontics is frequently performed in the clinic, but there have been no detailed studies or reports on the clinical outcomes of such treatment. We have performed local spatial adjustments during implant therapy and have obtained good results. Herein, we report analysis of clinical outcomes regarding dental implants with limited orthodontic treatment.

\section{MATERIALS AND METOHDS}

This study was conducted under the approval of the Institutional Review Board of the Seoul National University Bundang Hospital (IRB No. B-2010-640-102). Among the patients who underwent implant therapy at Seoul National University Bundang Hospital from 2010 to 2017, those who also underwent limited orthodontic treatment were investigated. Patients who met all of the following conditions were included in the study: (1) implant surgery performed by one oral and maxillofacial surgeon, (2) prosthodontic treatment completed, (3) limited orthodontic treatment, such as intrusion of an opposing tooth or uprighting of an adjacent tooth in preparation for implant treatment.

A total of 11 patients was included in the study, of which 5 underwent uprighting of a posterior tooth, and 6 underwent molar intrusion. One implant per patient was placed in either the maxillary or mandibular second premolar, first molar, or second molar regions.

Evaluation of treatment outcomes of the implants was performed through a medical chart review. Marginal bone level was measured on digital periapical radiographs collected with the paralleling cone technique. The success of each implant was judged based on the criteria reported by Zarb et al. in 1998, and survival was assessed $^{3)}$.

Analysis of the improvement of the horizontal or vertical spatial relationship through limited orthodontic cor- rection was performed through the following method. (1) Scanning of the diagnostic model before and after orthodontic treatment using a model scanner (Identica T500, Seoul, Korea), (2) Comparison and analysis of the stl files before and after orthodontic treatment using 3D modeling software (Rhinoceros 6, WA, USA), (3) Molar uprighting: Measurement of the amount of change in the shortest distance between adjacent teeth in the edentulous aspect to evaluate the amount of horizontal space acquired, (4) Intrusion: Construction of a plane consisting of three specific anatomical landmarks (buccal and palatal cusps) in two consecutive areas of the target tooth. Improvement of the vertical spatial relationship was evaluated before and after treatment by measuring the amount of change in the shortest distance from each cusp of the target tooth to the plane.

After completion of the entire treatment, the prognosis of the tooth that had undergone limited orthodontics was evaluated through survey of the medical record.

\section{RESULTS}

\section{Case summary}

The average age of the 11 patients ( 4 males and 7 females) in the study was 46.7 years, ranging from 26 to 63 years. Three patients had systemic disease and were on medication for diabetes, hypertension, or angina pectoralis, but all were well controlled or stable. All patients were nonsmokers. All 11 fixtures used for implant placement were made of titanium, 8 of which were Superline (Dentium, Suwon, Korea) and 2 were CMI IS (Neobiotech, Seoul, Korea), all of which possessed sandblasted, large grit, acid-etched surfaces. For the one remaining implant, a Tapered Screw-Vent (Zimmer Biomet, FL, United States) product with a surface coated with hydroxyapatite was used. The average diameter of the placed implant was 4.51 (3.6 to 5.0) $\mathrm{mm}$ with an average length of 8.86 (7 to 10$) \mathrm{mm}$. Guided bone regeneration (GBR) was performed in 3 patients in addition to implant therapy. Implant surgery was performed through the submerged method in 7 patients and through the non-submerged method in 4 patients. After surgery, no complications occurred in any patients until taking the impressions. Immediately after implant placement, primary stability 
Table 1 . Summary of implant treatment results

\begin{tabular}{|c|c|c|c|c|c|c|c|c|c|c|c|c|c|}
\hline \multirow{2}{*}{$\begin{array}{c}\text { Case } \\
\text { no. }\end{array}$} & \multirow{2}{*}{ Age } & \multirow{2}{*}{ Sex } & \multirow{2}{*}{ Site } & \multicolumn{2}{|c|}{ Fixture (mm) } & \multirow{2}{*}{$\begin{array}{l}\text { Surgery } \\
\text { type* }\end{array}$} & \multirow{2}{*}{$\begin{array}{c}\text { Combined } \\
\text { surgery }\end{array}$} & \multicolumn{2}{|c|}{ Stability (ISQ) } & \multirow{2}{*}{$\begin{array}{l}\text { F/U period } \\
\text { after loading } \\
\text { (month) }\end{array}$} & \multirow{2}{*}{$\begin{array}{l}\text { Bone loss } \\
\text { at latest } \\
\text { F/U (mm) }\end{array}$} & \multirow{2}{*}{ Success } & \multirow{2}{*}{ Survival } \\
\hline & & & & Diameter & Length & & & $1 \mathrm{st}$ & 2nd & & & & \\
\hline 1 & 54 & $\mathrm{~F}$ & 36 & 5.0 & 7.0 & $\mathrm{~S}$ & & 70 & 75 & 12.0 & 0.0 & 0 & 0 \\
\hline 2 & 41 & $M$ & 16 & 4.5 & 10.0 & $\mathrm{~S}$ & GBR & 55 & 65 & 19.1 & 0.0 & 0 & 0 \\
\hline 3 & 45 & $\mathrm{~F}$ & 46 & 3.6 & 8.0 & $\mathrm{~N}-\mathrm{S}$ & & 70 & 76 & 16.7 & 0.0 & 0 & 0 \\
\hline 4 & 26 & $M$ & 36 & 5.0 & 10.0 & $\mathrm{~N}-\mathrm{S}$ & & 80 & 80 & 53.2 & 0.2 & 0 & 0 \\
\hline 5 & 58 & $\mathrm{~F}$ & 45 & 4.0 & 8.0 & $S$ & GBR & 83 & 84 & 63.6 & 3.2 & $x$ & 0 \\
\hline 6 & 57 & $\mathrm{~F}$ & 47 & 4.5 & 8.0 & $\mathrm{~S}$ & & 72 & 74 & 31.2 & 0.0 & 0 & 0 \\
\hline 7 & 40 & $\mathrm{~F}$ & 37 & 4.7 & 10.0 & $S$ & GBR & 62 & 79 & 75.4 & 0.1 & 0 & 0 \\
\hline 8 & 44 & $\mathrm{~F}$ & 47 & 4.3 & 10.0 & $\mathrm{~S}$ & & 67 & 70 & 47.6 & 0.0 & 0 & 0 \\
\hline 9 & 34 & $\mathrm{~F}$ & 37 & 4.5 & 8.0 & $\mathrm{~N}-\mathrm{S}$ & & 71 & 75 & 0.6 & 0.0 & - & 0 \\
\hline 10 & 52 & $M$ & 47 & 4.5 & 10.0 & S & & 67 & 71 & 42.9 & 0.0 & 0 & 0 \\
\hline 11 & 63 & $M$ & 46 & 5.0 & 8.5 & $\mathrm{~N}-\mathrm{S}$ & & 87 & 81 & 41.4 & 0.0 & 0 & 0 \\
\hline
\end{tabular}

*S: submerged, N-S: non-submerged.

Table 2. Summary of limited orthodontic treatment results (uprighting)

\begin{tabular}{|c|c|c|c|c|c|}
\hline \multirow{2}{*}{$\begin{array}{l}\text { Case } \\
\text { no. }\end{array}$} & \multirow{2}{*}{ Site } & \multirow{2}{*}{ Treatment method } & \multicolumn{2}{|c|}{$\begin{array}{l}\text { Mesiodistal } \\
\text { space }(\mathrm{mm})\end{array}$} & \multirow{2}{*}{$\begin{array}{c}\text { Space } \\
\text { gained } \\
(\mathrm{mm})\end{array}$} \\
\hline & & & Pre & Post & \\
\hline 1 & $35 \sim 37$ & Partial DBS* & 9.1 & 10.1 & 1.0 \\
\hline 2 & $15 \sim 17$ & Mini screw implant & 4.9 & 8.0 & 3.1 \\
\hline 3 & $45 \sim 47$ & Open coil spring & 2.1 & 7.9 & 5.8 \\
\hline 4 & $35 \sim 37$ & Modified T loop & 6.3 & 9.6 & 3.4 \\
\hline 5 & $45 \sim 47$ & Open coil spring & 2.9 & 6.0 & 3.2 \\
\hline
\end{tabular}

*DBS: direct bonding system.

was measured using the Osstell Mentor device (Osstell, Gothenburg, Sweden). An average implant stability quotient (ISQ) value of 71.3 (55 to 87) was obtained, and secondary stability at the time of impression taking averaged 75.5 (65 to 84) ISQ. During the average follow-up period of 36.7 ( 1 to 64 ) months after functioning, all 11 implants survived and maintained normal function without any discomfort. Nine of 10 implants, excluding 1 with a follow-up period less than 1 year (\#9), met the success criteria (Table 1).

\section{1) Uprighting}

Uprighting of posterior teeth was performed in 5 patients and required an average of 11.4 months, ranging from 4.8 months to 23.4 months. In the case that required the longest time for orthodontic treatment (\#5), the patient did not visit the clinic for approximately 7 months during treatment. In 3 cases, orthodontic treatment was performed first to obtain some horizontal space with sub- sequent implant placement. In 2 cases, the implant was placed first, and then additional mesiodistal space was acquired. The average horizontal space of tooth loss before treatment was 5.1 (2.1 to 9.1) $\mathrm{mm}$. After uprighting of the posterior teeth, the mesiodistal space increased by approximately $3.3 \mathrm{~mm}$, exhibiting an average mesiodistal space of 8.3 (6.0 to 10.1) mm (Tables 2, 3). Average stability during implant treatment was 71.6 ISQ at the time of placement and 76.0 ISQ at the time of impression taking. Except for one case in which the success criteria were not met due to bone loss after placement, no remarkable bone loss was observed in the other implants until the most recent follow-up after functioning. In investigation of natural teeth that had undergone uprighting, one (\#2) issue occurred. The tooth was a maxillary second molar inclined mesially that had undergone uprighting treatment. It gradually exhibited increased mobility during orthodontic treatment and was extracted 27.0 months after the end of treatment. In the remaining 4 cases, all natural teeth showed good results without any specific findings.

The one implant that did not meet the success criteria was placed in a 58-year-old woman without systemic disease (\#5) during molar uprighting using an open coil spring in the edentulous right mandibular first molar region. At the time of implant placement, the alveolar bone was very narrow buccolingually, so demineralized freeze-dried bone allograft material and a titanium membrane were applied on the buccal side. However, after 1 week, soft tissue dehiscence and a partially exposed titanium membrane were observed. Therefore, we induced 
$4 \mathrm{Kim} \mathrm{I}$, et al: Clinical outcomes of dental implants combined with limited orthodontic treatment

Table 3. Timeline of implant treatment with limited orthodontic treatment

\begin{tabular}{|c|c|c|c|c|c|c|c|c|c|}
\hline \multirow{2}{*}{$\begin{array}{c}\text { Case } \\
\text { no. }\end{array}$} & \multirow{2}{*}{\multicolumn{7}{|c|}{ Treatment sequence and intervals between each treatments (months) }} & \multicolumn{2}{|c|}{ Treatment period (months) } \\
\hline & & & & & & & & Orthodontic & Total \\
\hline 1 & (i) & 7.5 & (o) & 5.5 & (f) & 2.2 & $(p)$ & 5.5 & 15.2 \\
\hline 2 & (i) & 7.7 & (o) & 4.1 & (p) & 0.8 & $(\mathrm{f})$ & 4.8 & 12.5 \\
\hline 3 & (o) & 6.0 & (i) & 6.8 & (p) & 1.4 & (f) & 14.2 & 14.2 \\
\hline 4 & (o) & 5.1 & (i) & 3.9 & $(p, f)$ & & & 9.0 & 9.0 \\
\hline 5 & (o) & 7.0 & (i) & 16.3 & (f) & 9.5 & (p) & 23.4 & 32.9 \\
\hline 6 & (o) & 3.3 & (i) & 7.8 & (p) & 0.7 & (f) & 11.8 & 11.8 \\
\hline 7 & (i) & 0.7 & (o) & 3.1 & (p) & 2.8 & (f) & 5.9 & 6.6 \\
\hline 8 & (o) & 9.1 & (i) & 5.8 & (p) & 0.7 & (f) & 15.6 & 15.6 \\
\hline 9 & (o) & 11.2 & (i) & 4.5 & $(p, f)$ & & & 15.7 & 15.7 \\
\hline 10 & (o) & 11.4 & (i) & 4.1 & (p) & 0.7 & (f) & 16.3 & 16.3 \\
\hline 11 & (o) & 11.3 & (i) & 4.6 & (f) & 2.4 & (p) & 15.8 & 18.3 \\
\hline
\end{tabular}

$\mathrm{i}$ : implant placement, $\mathrm{p}$ : end of prosthodontic treatment, o: start of orthodontic treatment, $\mathrm{f}$ : end of orthodontic treatment.
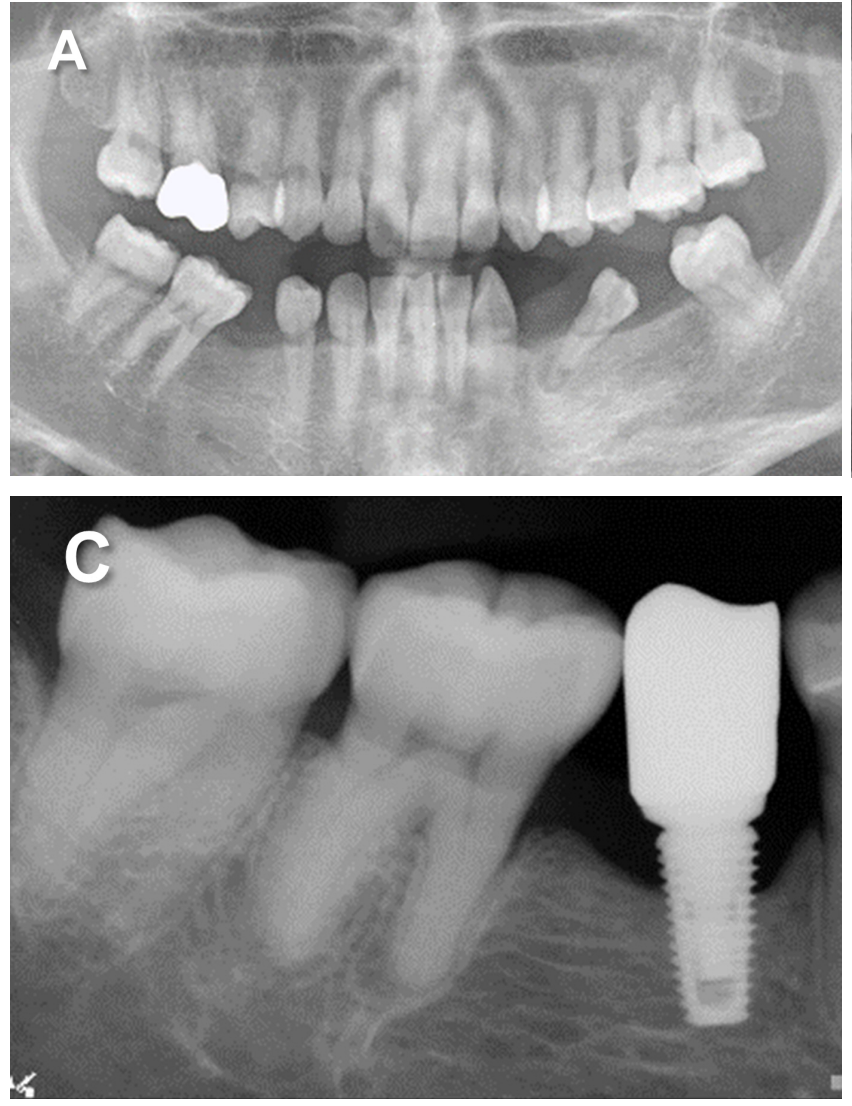

healing by secondary intention through frequent application of dressings. After loading, $3.2 \mathrm{~mm}$ of alveolar bone was lost within one year, but no additional bone loss was observed during the follow-up period of more than 5 years. This implant is functioning well without findings such as mobility, pain, discomfort in surrounding tissues, or prosthetic complications (Fig. 1).

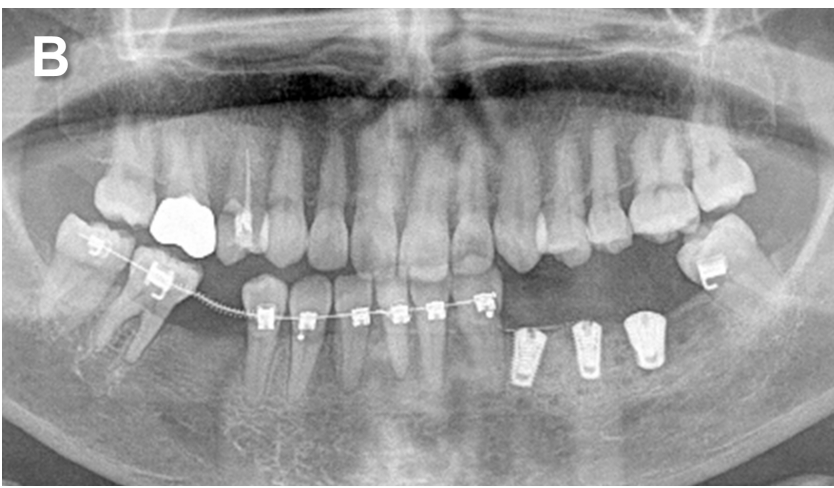

Fig. 1. Radiographs of a patient who underwent implant treatment of the right mandibular second premolar combined with uprighting of the posterior teeth. (A) Panoramic view at the first visit. The right mandibular posterior teeth were tilted toward the missing tooth area. (B) Panoramic view taken during posterior teeth uprighting using an open coil spring. (C) Intraoral periapical radiograph taken one year after loading. Marginal bone loss was observed. However, the implant survived and is being used with normal function without mobility, inflammation of the surrounding tissues, or patient discomfort at 63.6 months after loading.

\section{2) Intrusion}

Molar intrusion was performed on a total of 6 patients and required an average of 13.5 months, with a range from 5.9 months to 16.3 months. In 5 patients, orthodontic treatment was initiated first, while implant placement was performed first with subsequent molar intrusion in 1 patient. Using the diagnostic model before 
Table 4. Summary of limited orthodontic treatment results (intrusion)

\begin{tabular}{|c|c|c|c|c|c|c|c|c|c|c|c|}
\hline \multirow{3}{*}{ Case no. } & \multirow{3}{*}{ Site } & \multirow{3}{*}{ Treatment method } & \multicolumn{6}{|c|}{ Amount of extrusion (mm) } & \multirow{2}{*}{\multicolumn{3}{|c|}{ Amount of intrusion $(\mathrm{mm})$}} \\
\hline & & & \multicolumn{3}{|c|}{ Pre } & \multicolumn{3}{|c|}{ Post } & & & \\
\hline & & & MB & $\mathrm{DB}$ & MP & MB & DB & MP & MB & DB & MP \\
\hline 6 & 17 & TPA* & -1.6 & -0.6 & -3.1 & 0.8 & 0.8 & -0.3 & 2.4 & 1.4 & 2.8 \\
\hline 7 & 27 & TPA & -0.1 & 1.1 & -1.2 & 0.1 & 0.9 & 1.2 & 0.2 & -0.2 & 2.4 \\
\hline 8 & 17 & Partial $\mathrm{DBS}^{\dagger}$ & -1.1 & -1.5 & -2.7 & 1.0 & 1.2 & 0.9 & 2.1 & 2.7 & 3.6 \\
\hline 9 & 27 & TPA & -2.5 & -2.8 & -2.9 & 0.3 & 0.2 & 0.9 & 2.8 & 3.0 & 3.8 \\
\hline 10 & 17 & Partial DBS & -0.4 & 0.5 & -1.4 & -0.3 & 0.1 & 0.2 & 0.1 & -0.4 & 1.6 \\
\hline 11 & 16 & Mini screw implant & -2.5 & -2.5 & -3.2 & 0.4 & 0.3 & -0.1 & 2.9 & 2.8 & 3.1 \\
\hline
\end{tabular}

*TPA: transpalatal arch, ${ }^{\dagger}$ DBS: direct bonding system.
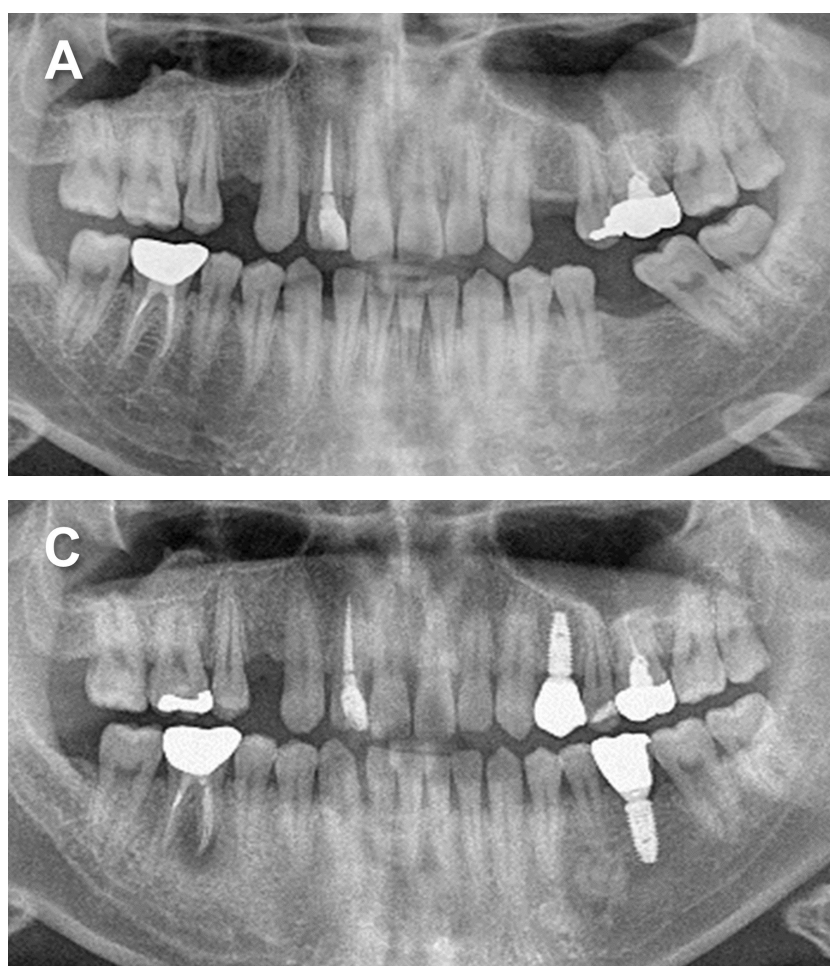

orthodontic treatment, the average amount of extrusion of the molar was $1.4 \mathrm{~mm}$ for mesiobuccal cusps, $1.0 \mathrm{~mm}$ for distobuccal cusps, and $2.4 \mathrm{~mm}$ for mesiopalatal cusps. Through limited orthodontic treatment, intrusion of the mesiobuccal cusps, distobuccal cusps, and mesiopalatal cusps was $1.8 \mathrm{~mm}, 1.6 \mathrm{~mm}$, and $3.0 \mathrm{~mm}$, respectively (Tables 3, 4). During implant placement, the average primary stability was 71.0 ISQ, while secondary stability was 75.0 ISQ. All implants exhibited good progress without bone loss or other issues of discomfort until the most recent follow-up. In addition, all six teeth that underwent molar intrusion exhibited no remarkable abnormal findings during the follow-up period.

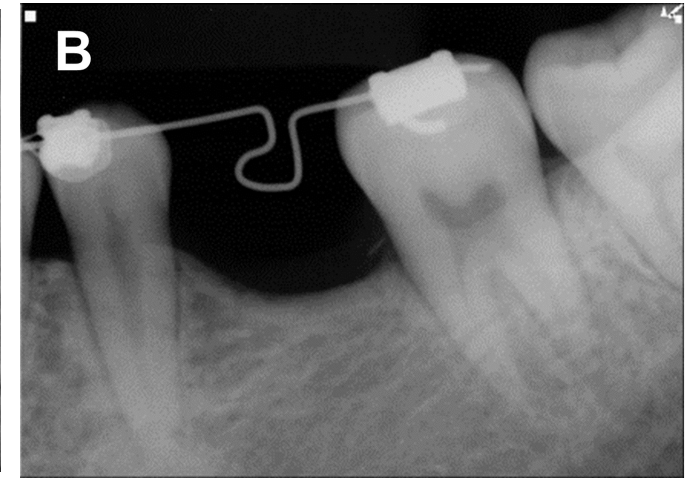

Fig. 2. Radiographs during implant treatment combined with uprighting of the posterior teeth in the left mandible. (A) Panoramic view taken at the first visit. The left mandibular first molar was lost, and tilting of the molars was observed. (B) Intraoral radiograph during progression of orthodontic treatment. A modified T loop was used. (C) Panoramic view taken 54 months after completion of implant treatment.

\section{Case presentation}

\section{1) Uprighting (\#4)}

A 26-year-old man with no systemic disease visited the clinic for implant therapy in the left mandibular first molar and left maxillary first premolar regions, where teeth had been removed 3 4 years prior. The adjacent teeth around the missing left mandibular first molar were tilted toward the edentulous area. The mesial inclination of the second molar was so severe that the patient was referred to the orthodontic clinic (Fig. 2A). Although it was ideal to perform generalized orthodontic treatment, only limited correction of the edentulous aspect of the left mandible was planned at the request of the patient. 

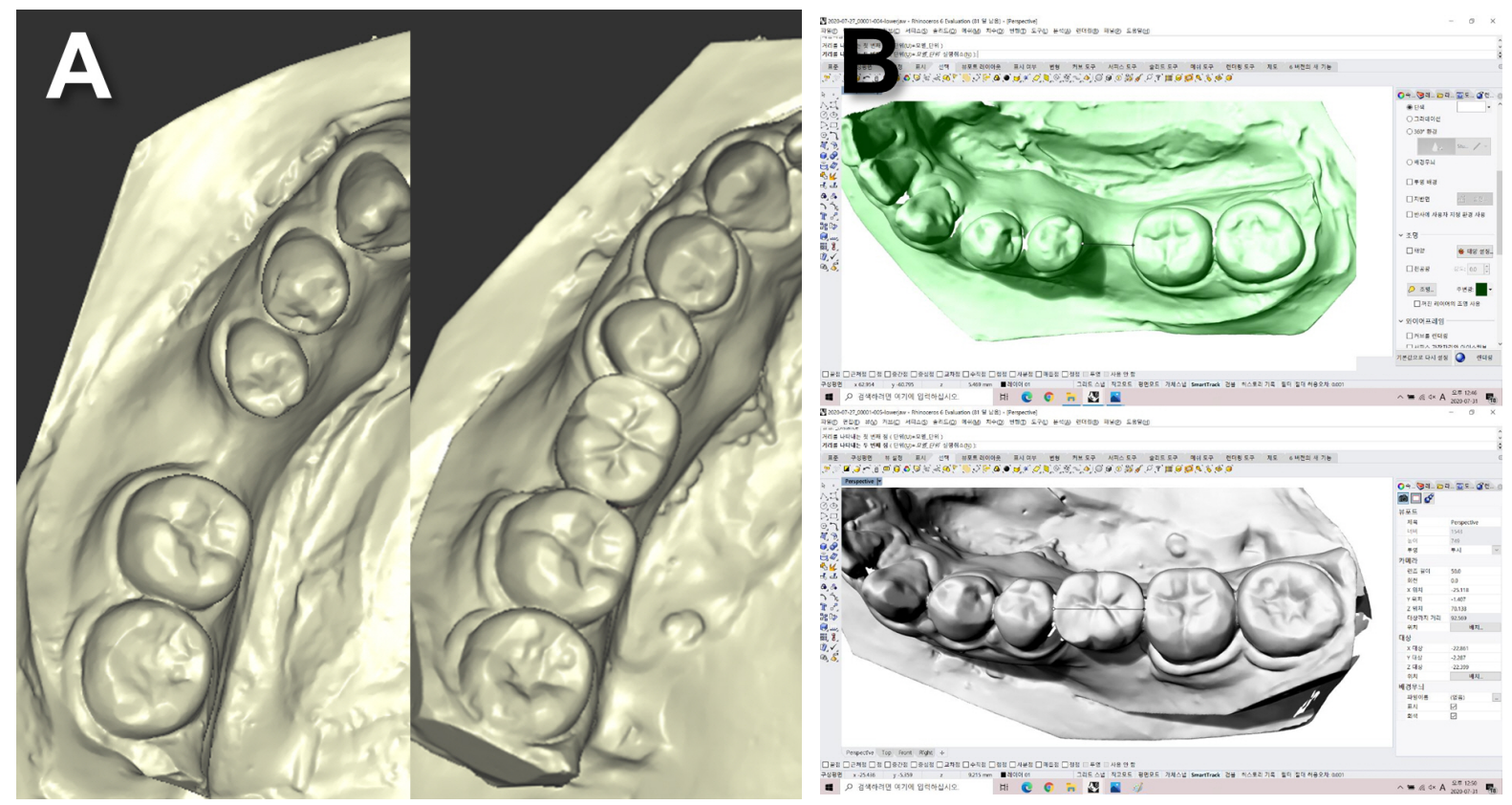

Fig. 3. A case of implant therapy with posterior teeth uprighting. (A) Diagnostic model scan before and after treatment. (B) The mesiodistal space before and after treatment using 3D modeling software.

The mandibular premolar and molar were uprighted using a modified $\mathrm{T}$ loop. After approximately 5 months of limited orthodontic treatment, the mesiodistal space was adequate to allow implant placement in the left mandibular first molar region. A CMI IS implant (Neobiotech, Seoul, Korea) with a diameter of $5 \mathrm{~mm}$ and a length of $10 \mathrm{~mm}$ was used. Primary stability immediately after implant installation was good at 80 ISQ, and a healing abutment was placed. No complications occurred after the operation, and an impression was taken approximately 3 months later and restored with a porcelain fused gold crown (Fig. 2B, C). Orthodontic treatment was completed at the same time as installation of the implant prosthesis. The duration of total treatment was 9.0 months.

The edentulous mesiodistal space was measured at 6.3 $\mathrm{mm}$ before treatment and $9.6 \mathrm{~mm}$ after completion of orthodontic treatment. Through limited orthodontic treatment for approximately 9 months, implant restoration with an appearance similar to that of the natural tooth was achieved by securing a $3.36 \mathrm{~mm}$ mesial space (Fig. 3).

During the follow-up period of approximately 54 months after implant prosthesis restoration, marginal bone level remained constant and no peri-implantitis or prosthetic complications were observed. Afterward, no specific findings were observed even in the teeth that had undergone orthodontic treatment.

\section{2) Intrusion (\#6)}

A healthy 57-year-old woman visited the clinic for implant therapy in the right mandibular second molar. The right mandibular first molar exhibited chronic periodontitis with loss of alveolar bone to the apical region, requiring its extraction at the first visit. The right mandibular second molar was lost more than 10 years prior, causing extrusion of the opposing right maxillary second molar and creating insufficient interocclusal space (Fig. $4 \mathrm{~A})$. Therefore, we referred the patient to the orthodontics department.

Molar intrusion was performed using a transpalatal arch, and the implants were placed in the right mandibular first and second molar sites approximately 3 months after the start of orthodontic treatment. Two Superline (Dentium, Suwon, Korea) implants with a length of $8 \mathrm{~mm}$ were placed in the sites. Implants with a diameter of $6 \mathrm{~mm}$ or $4.5 \mathrm{~mm}$ were placed in the first and second molar regions, respectively. The primary stability of both implants was greater than 72 ISQ, and second-stage surgery was performed 5 months later with secondary stabilities greater than 74 ISQ. There were no 

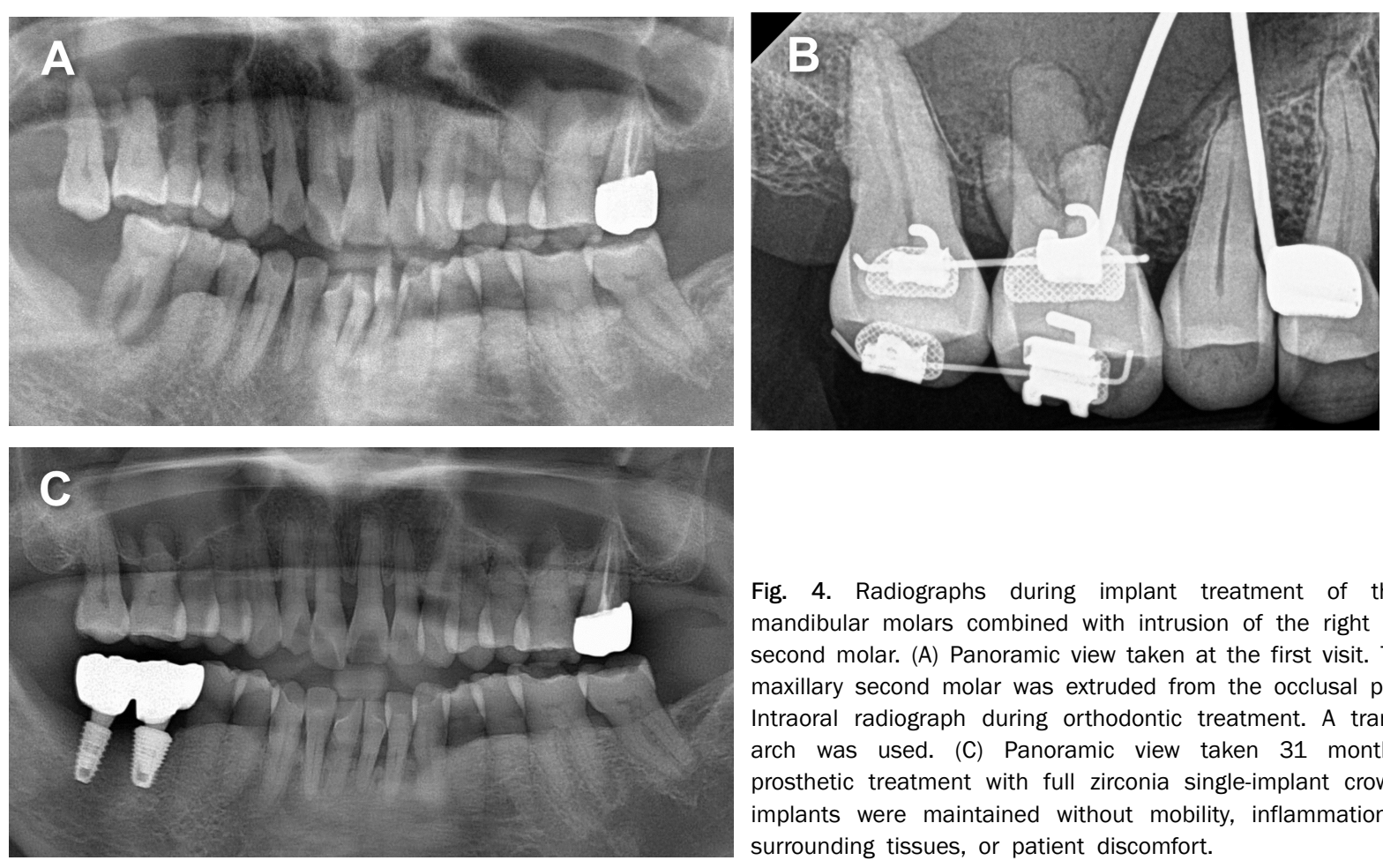

Fig. 4. Radiographs during implant treatment of the right mandibular molars combined with intrusion of the right maxillary second molar. (A) Panoramic view taken at the first visit. The right maxillary second molar was extruded from the occlusal plane. (B) Intraoral radiograph during orthodontic treatment. A transpalatal arch was used. (C) Panoramic view taken 31 months after prosthetic treatment with full zirconia single-implant crowns. The implants were maintained without mobility, inflammation of the surrounding tissues, or patient discomfort.
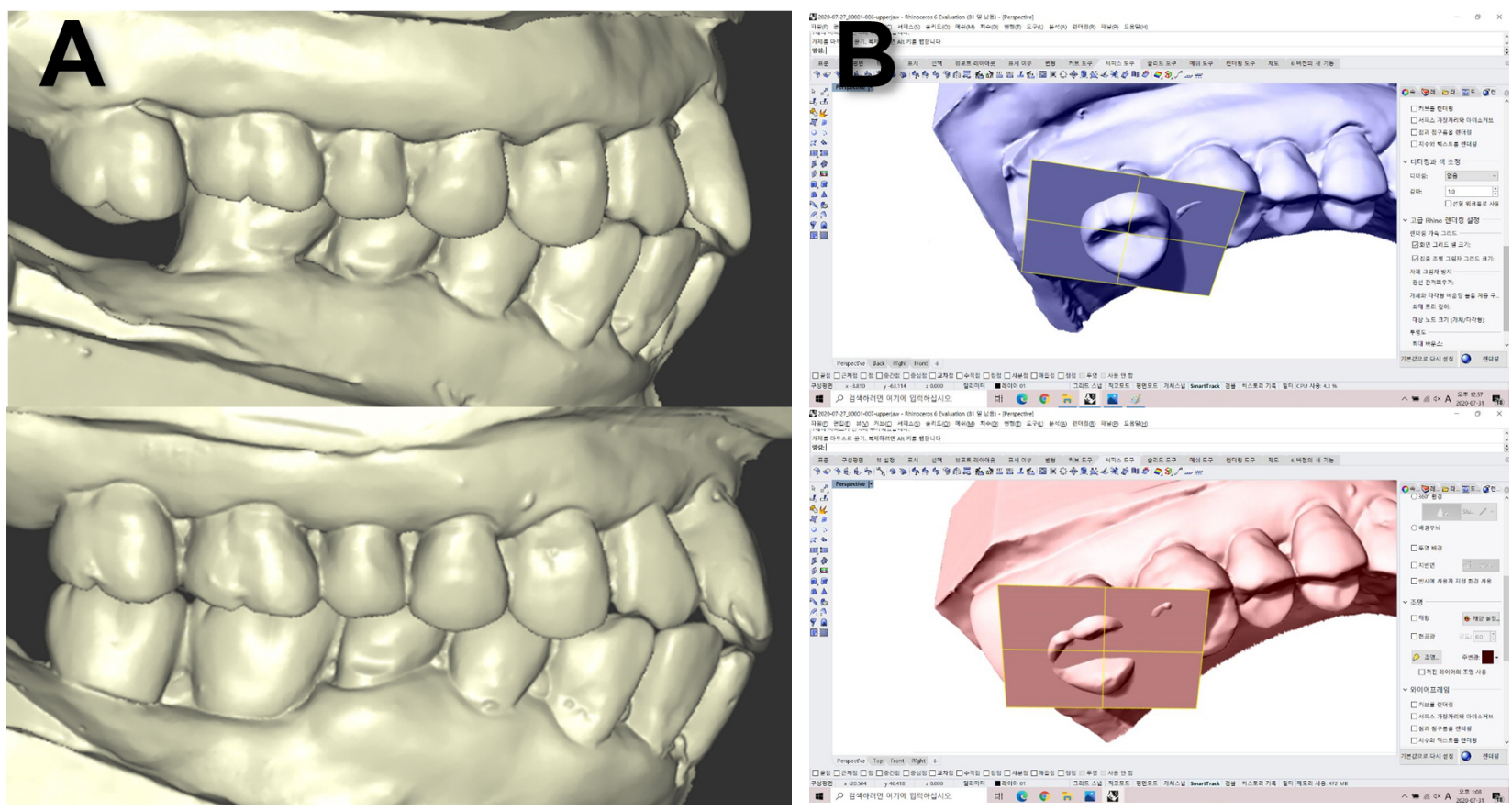

Fig. 5. A case of implant therapy with molar intrusion. (A) Diagnostic model scan before and after treatment. (B) The amount of intrusion before and after treatment of the maxillary second molar using 3D modeling software.

complications related to the surgery. An impression was taken 2 months after the second surgery, and completed prosthetic restorations involved full zirconia non-splinted crowns. Limited orthodontic treatment was concluded 3 weeks after completion of implant treatment (Fig. 4B, C). The total duration of treatment was 11.8 months.

Through orthodontic treatment, the right maxillary second molar was intruded by approximately $2.4 \mathrm{~mm}$ 
(mesiobuccal cusp $2.3 \mathrm{~mm}$, distobuccal cusp $1.4 \mathrm{~mm}$, and mesiopalatal cusp $2.8 \mathrm{~mm}$ ) (Fig. 5).

During follow-up for approximately 31 months after completion of implant therapy, the right mandibular second molar implant was functioning normally without marginal bone loss, soft tissue inflammation, or prosthetic complications. In addition, the right maxillary second molar that had undergone orthodontic intrusion exhibited no specific findings such as increased mobility, inflammation, or discomfort.

\section{DISCUSSION}

Posterior teeth can cause several problems if left untreated after extraction. After loss of a molar, opposite tooth extrude in $83 \sim 92 \%$ of cases, with the amount of extrusion reported to vary from less than $0.5 \mathrm{~mm}$ to $5.4 \mathrm{~mm}^{4,5)}$. In addition, $39.4 \%$ of patients who lost their first molar experienced mesial incline of the second molar as this phenomenon is more common in the mandible compared to the maxilla ${ }^{6,7)}$. These changes that occur after posterior tooth extraction increase the difficulty of implant treatment. If the mesiodistal space of the edentulous region is reduced due to drifting after tooth extraction, it is not possible to place an implant with a desired diameter due to restrictions in surgical and prosthetic treatment procedures. If the mesially tilted posterior teeth continue to function without orthodontic correction, the occlusal forces cannot be transmitted in the direction of the long tooth axis, resulting in reduced mastication efficiency and progressive damage to the underlying alveolar bone ${ }^{2,8)}$. In addition, reduced interocclusal space due to extruded teeth may limit implant prosthetic treatment. Misch et al. reported that the ideal occlusal space for implant therapy is $8-12 \mathrm{~mm}$ vertically ${ }^{9,10)}$. Kim et al. stated that a vertical interocclusal height of at least $6 \mathrm{~mm}$ is required when performing cement-retained implant prosthetic restorations ${ }^{11)}$. Therefore, for implant treatment, the process of creating a local environment similar to the condition before the loss of the posterior tooth as much as possible is achieved by restoring the horizontal or vertical space above a certain level.

Chun et al. reported a case in which the interocclusal space was obtained by intruding the opposing tooth with a molar intrusion arch during implant treatment in the mandibular posterior region ${ }^{12)}$. Sekine et al. presented a case of implant treatment performed after orthodontic correction of an inclined mandibular molar and emphasized the importance of improving local occlusal relationships in implant dentistry ${ }^{13}$. Hwang et al. reported three cases of successful implant restoration in patients with one or two tooth edentulous sites by applying uprighting or intrusion forces of the posterior teeth with the aid of orthodontic mini screws ${ }^{14)}$. Ahn et al. performed limited orthodontic treatment of inclined posterior dentition for implant therapy in a patient whose occlusion was collapsed due to multiple areas of tooth loss, thereby securing the necessary space for implant placement and aesthetic and functional implant treatment ${ }^{15)}$. Most of these studies related to implant therapy with limited orthodontic treatment were case reports, with clinical research papers hard to be found. Therefore, this review is considered to be of great clinical significance.

In this study, as already mentioned, 10 of a total of 11 implants satisfied the success criteria. One failed implant resulted from a locally unfavorable environment where the width of the alveolar crest was very narrow at the time of implant surgery. Furthermore, the patient did not maintain follow-up appointments during treatment and did not show for a long period of time $(6$ months after implant placement and 7 months after temporary prosthesis restoration), resulting in lack of proper management that may have acted as a factor to accelerate bone loss.

All 11 implants survived during an average observation period of 36.7 months (1 64 months) post function. This result is superior to the 91.1 93.6\% survival rate reported in other studies with similar observation periods conducted on single molars ${ }^{16,17)}$. However, since this study had a small population number, direct comparison of the survival rate itself may not be appropriate, and further research supplementing these matters is necessary.

As a result of prognostic analysis of teeth that had undergone limited orthodontic treatment in our study, only one tooth was extracted due to increased mobility - a maxillary second molar that had been treated for uprighting. Periodontal issues may occur on the mesial aspect of an inclined molar. Therefore, if clinicians are planning to place implants with uprighting of inclined molars, one must carefully examine the periodontal status of the tilted 
teeth during the entire process, from treatment planning to follow-up. For such cases, application of a certain periodontal disease prevention protocol is recommended ${ }^{18,19)}$.

In future studies, it would be of great significance to analyze and present the limits of angulation that can be corrected on inclined posterior teeth and the amount of intrusion on extruded molars associated with implant treatment.

\section{CONCLUSIONS}

An approximately $3.3 \mathrm{~mm}$ gain of mesiodistal space in the missing tooth region was confirmed through uprighting of inclined posterior dentition. The interocclusal space, which was initially insufficient for implant treatment, was improved by intruding the mesiobuccal cusps, distobuccal cusps, and mesiopalatal cusps by approximately $1.7 \mathrm{~mm}, 1.6 \mathrm{~mm}$, and $2.9 \mathrm{~mm}$, respectively. Eleven dental implants placed in 11 patients survived for an average of 36.7 months after loading and are functioning well without discomfort. Despite drawbacks that implant therapy with limited orthodontic treatment has issues including prolonging the entire treatment period and increasing treatment cost, this treatment method could be seen as a prognostic treatment method with a satisfactory prognosis.

\section{CONFLICT OF INTEREST}

The authors declare that they have no conflict of interests.

\section{ORCID}

Il-hyung Kim, https:/ / orcid.org/0000-0003-1386-6391

Hyeong Gi Kim, https://orcid.org/0000-0003-4730-0396

Pil-Young Yun, https://orcid.org/0000-0001-6097-1229

Young-Kyun Kim, https://orcid.org/0000-0002-7268-3870

\section{REFERENCES}

1. Craddock HL, Youngson CC, Manogue M, Blance A. Occlusal changes following posterior tooth loss in adults. Part 1: a study of clinical parameters associated with the extent and type of supraeruption in unopposed posterior teeth. J Prosthodont 2007;16:485-94.

2. Jivraj S, Chee W. Treatment planning of implants in posterior quadrants. Br Dent J 2006;201:13-23.

3. Zarb GA, Albrektsson T. Consensus report: towards optimized treatment outcomes for dental implants. J Prosthet Dent 1998;80:641.

4. Craddock HL, Youngson CC. A study of the incidence of overeruption and occlusal interferences in unopposed posterior teeth. Br Dent J 2004;196:341-8.

5. Craddock HL. Occlusal changes following posterior tooth loss in adults. Part 3. A study of clinical parameters associated with the presence of occlusal interferences following posterior tooth loss. J Prosthodont 2008;17:25-30.

6. Artun J, Thalib L. Mesial migration and loss of first molars among young adolescents in Kuwait. Community Dent Health 2011;28:154-9.

7. Varshney A, Hegde MN, Yelapure M. Prevalence of Missing First Molar in South Canara District Population. Int J Med Oral Res 2018;3:26-30.

8. Stern N, Revah A, Becker A. The tilted posterior tooth. Part I: etiology, syndrome, an prevention. J Prosthet Dent 1981;46: 404-7.

9. Misch CE, Goodacre CJ, Finley JM, Misch CM, Marinbach M, Dabrowsky T, et al. Consensus conference panel report: crown-height space guidelines for implant dentistry-part 1. Implant Dent 2005;14:312-8

10. Misch CE, Goodacre CJ, Finley JM, Misch CM, Marinbach M, Dabrowsky T, et al. Consensus conference panel report: crown-height space guidelines for implant dentistry-part 2. Implant Dent 2006;15:113-21.

11. Kim SM, Choe SH, Song YW, Kang JH, Cha JK, Lee JS, et al. Consideration of minimal interocclusal distance for implant-supported prosthesis. J Korean Acad Oral Maxillofac Implantol 2017;21:54-64.

12. Chun YS, Row J, Yang SJ, Cha HS, Han JS. Management of extruded maxillary molars to accommodate a mandibular restoration: a clinical report. J Prosthet Dent 2000;83:604-6.

13. Sekine H, Miyazaki H, Takanashi T, Furuya K, Matsuzaki F, Taguchi $T$, et al. Dental implant treatment after improvement of oral environment by orthodontic therapy. Bull Tokyo Dent Coll 2012;53:109-17.

14. Hwag JY, Lee NK, Yun PY, Kim YK. Limited orthodontic treatment using orthodontic mini-screws for implant placement: Case reports. Oral Biol Res 2012;36:78-83

15. Ahn A, Koak JY, Heo SJ, Kim SK. Full mouth rehabilitation using orthodontic treatment and implants in patient with collapsed occlusion: A case report. J Korean Acad Prosthodont 2019;57: 439-47.

16. Kim YK, Kim SG, Yun PY, Hwang JW, Son MK. Prognosis of single molar implants: a retrospective study. Int J Periodontics Restorative Dent 2010;30:401-7.

17. Levin L, Laviv A, Schwartz-Arad D. Long-term success of implants replacing a single molar. J Periodontol 2006;77: 1528-32.

18. Lubow RM, Cooley RL, Kaiser D. Periodontal and restorative aspects of molar uprighting. J Prosthet Dent 1982;47:373-6.

19. Simon RL. Rationale and practical technique for uprighting mesially inclined molars. J Prosthet Dent 1984;52:256-9. 